\title{
Burnout Among English Language Teachers In Malaysia
}

Jayakaran Mukundan, Universiti Putra Malaysia

Koroush Khandehroo, Universiti Putra Malaysia

\begin{abstract}
The phenomenon of burnout has always been under scrutiny, especially with reference to the teachers and their demographics. This study has deliberately focused on the English teachers' burnout and its relation with their demographics of age and workload in Malaysia. The findings showed that burnout is evident at high levels in all dimensions. In addition, some age and workload categories demonstrated significant relations with emotional exhaustion, depersonalization and reduced personal accomplishment. The findings would help school administrators consider such factors as important in the effectiveness of English teachers.
\end{abstract}

Keywords: burnout, emotional exhaustion, depersonalization, reduced personal accomplishment, workload, age

\section{INTRODUCTION}

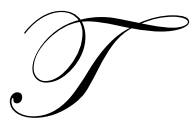

he phenomenon of burnout beginning with the intense interactions in working with people is quite usual and has been the issue of focus in different human service occupations including health and mental care professions (Freudenburger and North, 1985; Maslach and Jackson, 1982; Pines and

Maslach, 1984).

Burnout among teachers has always been an important issue since teaching is a profession through which stressors coming from the students and context affect their inner feelings and consequently their performance. Because students are probably the direct victims of the teachers' weak performance caused by the phenomenon, the issue of burnout is worth being elaborated. The concept was first introduced by Freudenbeger in 1974 as wearing down or depleting energy (Freudenburger and North, 1985). Maslach, one of the pioneering figures studying burnout, has defined it as a syndrome of physical and emotional exhaustion including the development of negative job attitudes, poor professional self concept, and low empathetic concern for clients (Maslach and Pines, 1984). Accordingly, she presents the three dimensions of burnout as Emotional Exhaustion, Depersonalization, and Reduced Personal Accomplishment.

Emotional Exhaustion refers to the feelings of over extension and exhaustion resulting from daily conflict in work. It is particularly defined as the lack of enthusiasm and the sense of emotional draining by other people among teachers (Gavrilovici, L. O. 2007). Depersonalization indicates the development of negative attitudes and impersonal behaviors to people in relation to the profession such as students for teachers Depersonalization is also the emotionally dry and detached manner of relating to others. Personal accomplishment is the sense of personal fulfillment coming with self-esteem that is negatively related to burnout; the more people suffer from burnt out, the worse they feel about their personal accomplishment. Lack of feeling of success and accomplishment among teachers is defined as reduced professional efficacy, which is the negative belief of self capability in classroom.

Some individual characteristics have been studied as they relate to teacher burnout. Gender is one of the factors that distinguishes patterns of burnout characteristics in which men generally achieve higher scores on Depersonalization across all grade levels (e.g. Lau, Yuen, and Chan, 2005), indicating more negative thoughts toward students (Schwab and Iwanicki, 1982), while females reported higher Emotional Exhaustion and reduced Personal Accomplishment scores (Lau et al., 2005). Studies focusing on age and teaching experience as factors relating to the phenomenon of burnout have been to a great extent inconsistent, principally when the analyses have 
covered different communities and cultures. For example, despite different findings on the function of age in expecting burnout among public school teachers in the U.S. (e.g. Anderson and Iwanicki, 1984; Byrne, 1999; Maslach and Jackson, 1981; Schwab, Jackson, and Schuler, 1986), a newly conducted study among Hong Kong educators proved that teachers in the youngest age group were more burnt out than the older ones (Lau et al., 2005).

Although demographic factors have been found relating to the phenomenon of burnout among teachers in different studies, very few of them have ever been conducted in the scope of subject specific teachers' burnout. This study has focused on English teachers in Malaysia since they carry the burden of teaching English in a so called ESL context where nearly the entire population's first language is not English.

Sources of burnout according to Schwab and Iwanicki (1982) are introduced as background, individual personality, and organizational factors. Educational level, type of graduation school, etc. are related to the background category while age, gender, number of children and the like are put in the individual personality category, and class size, work environment, workload and the like are recognized as organizational factors of the sources of teacher burnout.

This study has aimed to determine the burnout level of the primary and secondary school teachers in Malaysia as measured by their scores on Emotional Exhaustion, Depersonalization and Personal Accomplishment. The secondary purpose of this study is to find out if significant relationships exist between burnout dimensions and the participants' age and workload (based on their teaching hours per week).

The study can be significant since the related findings help school system administrators pay more attention to the factors contributing to satisfaction, or engagement of the teachers.

\section{METHODOLOGY}

The sample of the study was the 184 participants randomly selected from which the response rate was $65 \%$. About $63 \%$ of whom were females. They were all English teachers in primary and secondary schools. As for their age range, $61 \%$ of the participants were between the ages of 26 to 45 .

In order to measure the burnout level of the teachers, the Maslach Burnout Inventory (MBI) Educators Survey (1986), with 22 items was utilized. The questionnaire encompasses three subscales of Emotional Exhaustion with nine items, Depersonalization with five items, and Personal Accomplishment with eight items. MBI describes burnout syndrome in terms of (a) high levels of Emotional Exhaustion, (b) high levels of Depersonalization, (c) reduced Personal Accomplishment.

The internal reliability of MBI-ES reported by Maslach, Jackson, and Leiter (1996) is acceptable since Cronbach's alphas for emotional exhaustion were .90 , for depersonalization 79 , and for personal accomplishment .71. Test-retest coefficients were .82 for emotional exhaustion, .60 for depersonalization, and .80 for personal accomplishment (Maslach, Jackson, and Leiter, 1996).

Gold, Roth, Wright, Michael, and Chen (1992) tested for factorial validity of MBI with a sample of beginning teachers with one to three years of teaching experience. The analysis discovered three identifiable factor dimensions related to the three constructs. In a factor analysis, the correlation between emotional exhaustion and depersonalization was .76, it was -.65 between emotional exhaustion and personal accomplishment, and -.74 between depersonalization and personal accomplishment. Gold et al. (1992, p.766) found the MBI to have "considerable potential validity in identifying those beginning teachers who may have a substantial risk for burnout".

The demographic information about the teachers was provided by a demographic questionnaire. The survey was prepared to gain information on the primary and secondary English school teachers', age, and workload. 


\section{RESULTS}

SPSS version 16 was used to analyze the data. One-sample t-test was the statistical procedure employed on the scores taken form emotional exhaustion, depersonalization, and reduced personal accomplishment. Low, moderate, and high are the three typical levels of burnout; however, only high levels of the three dimensions were considered to be elaborated in this study.

According to the literature there are studies which suggest the score ranges for each subscale to define high level of burnout (Rosenberg and Pace, 2006). Emotional Exhaustion and Depersonalization scores exceeding 27 and 13 respectively and Reduced Personal Accomplishment scores below 31 are considered to be high.

As indicated in table 1 , all burnout dimensions are presented to be significantly high since the significant $\mathrm{p}$ 0.001 is less than 0.05 among all participants who are in the high level intervals.

Table 1

Statistics and one-sample t-test for burnout dimensions

\begin{tabular}{|lcccccccc|}
\hline \multicolumn{1}{|c}{ Burnout } & N & Mean & SD & $\begin{array}{c}\text { Test } \\
\text { Value }\end{array}$ & $\begin{array}{c}\text { Sig. (2- } \\
\text { tailed) }\end{array}$ & $\begin{array}{c}\text { Mean } \\
\text { Difference }\end{array}$ & $\begin{array}{c}\text { 95\% Confidence } \\
\text { Interval of the } \\
\text { Difference } \\
\text { Lower } \\
\text { Upper }\end{array}$ \\
\hline $\begin{array}{l}\text { Emotional Exhaustion } \\
\text { Depersonalization }\end{array}$ & 120 & 31.30 & 8.33 & 27 & 0.001 & 4.30 & 2.80 & 5.81 \\
$\begin{array}{l}\text { Low level of Personal } \\
\text { Accomplishment }\end{array}$ & 120 & 16.7 & 6.12 & 13 & 0.001 & 3.70 & 2.59 & 4.80 \\
\hline
\end{tabular}

To determine whether age and workload groups represent significance in high levels of emotional exhaustion, depersonalization, and reduced personal accomplishment, one-sample t-test was employed for the scores of those participants in each group. Table 2 represents that teachers between age range of $<25$ to 45 face emotional exhaustion, yet those older than 46 do not have this predicament as high.

Table 2

Statistics and one-sample t-test for Emotional Exhaustion with reference to age

\begin{tabular}{|ccccccccc|}
\cline { 2 - 9 } \multicolumn{1}{l|}{} & \multicolumn{10}{c|}{ Emotional Exhaustion } \\
\hline Age Group & $\mathbf{N}$ & Mean & SD & $\begin{array}{c}\text { Test } \\
\text { Value }\end{array}$ & $\begin{array}{c}\text { Sig. (2- } \\
\text { tailed) }\end{array}$ & Mean Difference & $\begin{array}{c}\text { 95\% Confidence Interval } \\
\text { of the Difference } \\
\text { Lower }\end{array}$ \\
Upper
\end{tabular}

Depersonalization in diverse age groups as presented in table 3 is significantly high among participants older than 25 whereas for age group of $<25$, since the significant value is $(p=.222>\alpha)$, it can not be identified as significantly high.

Table 3

Statistics and one-sample t-test for Emotional Exhaustion with reference to age

\begin{tabular}{|ccccccccc|}
\cline { 2 - 9 } \multicolumn{1}{l|}{} & \multicolumn{10}{c|}{ Depersonalization } \\
\hline Age Group & $\mathbf{N}$ & Mean & SD & $\begin{array}{c}\text { Test } \\
\text { Value }\end{array}$ & $\begin{array}{c}\text { Sig. (2- } \\
\text { tailed) }\end{array}$ & Mean Difference & $\begin{array}{c}\text { 95\% Confidence Interval } \\
\text { of the Difference } \\
\text { Lower }\end{array}$ \\
\hline $\mathbf{2 5}$ & 24 & 14.12 & 4.38 & 13 & 0.222 & 1.12 & -0.72 & 2.97 \\
$\mathbf{2 6 - 3 5}$ & 37 & 17.21 & 6.62 & 13 & 0.001 & 4.21 & 2.00 & 6.42 \\
$\mathbf{3 6 - 4 5}$ & 37 & 16.43 & 6.27 & 13 & 0.002 & 3.43 & 1.33 & 5.52 \\
$>\mathbf{4 6}$ & 22 & 19.09 & 5.85 & 13 & 0.001 & 6.09 & 3.49 & 8.68 \\
\hline
\end{tabular}


The highest and lowest age groups (those younger than 25 and older than 45), as shown in table 4, characterize a significantly high level of reduced personal accomplishment. On the other hand, the age range between 26 and 45 confirms that they do not indicate any significant sign of this aspect of burnout.

Table 4

Statistics and one-sample t-test for Reduced Personal Accomplishment with reference to age Reduced Personal Accomplishment

\begin{tabular}{|c|c|c|c|c|c|c|c|c|}
\hline & & \multirow{3}{*}{ Mean } & & \multirow{3}{*}{$\begin{array}{c}\text { Test } \\
\text { Value }\end{array}$} & rsonal A & \multirow{3}{*}{ Mean Difference } & & \\
\hline \multirow[t]{2}{*}{ Age Group } & \multirow[t]{2}{*}{$\mathbf{N}$} & & \multirow[t]{2}{*}{ SD } & & \multirow{2}{*}{$\begin{array}{l}\text { Sig. (2- } \\
\text { tailed) }\end{array}$} & & \multicolumn{2}{|c|}{$\begin{array}{l}\text { 95\% Confidence Interval } \\
\text { of the Difference }\end{array}$} \\
\hline & & & & & & & Lower & Upper \\
\hline$<25$ & 24 & 20.58 & 7.99 & 31 & 0.001 & -10.41 & -13.79 & -7.03 \\
\hline $26-35$ & 37 & 30.51 & 4.27 & 31 & 0.490 & -0.48 & -1.91 & 0.93 \\
\hline $36-45$ & 37 & 29.83 & 6.71 & 31 & 0.299 & -1.16 & -3.40 & 1.07 \\
\hline$>46$ & 22 & 18.45 & 8.56 & 31 & 0.001 & -12.54 & -16.34 & -8.74 \\
\hline
\end{tabular}

Workload, on the basis of teaching hours per week, was categorized in four interval groups of <10, 11-20, 21-30, and $>30$ and was scrutinized with relation to each of the burnout dimensions. In table 5 , the three categories of 11-20, 20-30, and $>30$ show a significant relation with reference to the emotional exhaustion. However, the first group consisting of 22 teachers with less than 10 hours of teaching did not show a high degree of emotional exhaustion.

Table 5

Statistics and one-sample t-test for Emotional Exhaustion with reference to workload

\begin{tabular}{|c|c|c|c|c|c|c|c|c|}
\hline \multirow{3}{*}{$\begin{array}{c}\text { Workload } \\
\text { Hours/Week }\end{array}$} & \multicolumn{8}{|c|}{ Emotional Exhaustion } \\
\hline & \multirow[t]{2}{*}{$\mathbf{N}$} & \multirow[t]{2}{*}{ Mean } & \multirow[t]{2}{*}{ SD } & \multirow[t]{2}{*}{$\begin{array}{l}\text { Test } \\
\text { Value }\end{array}$} & \multirow[t]{2}{*}{$\begin{array}{l}\text { Sig. (2- } \\
\text { tailed) }\end{array}$} & \multirow[t]{2}{*}{$\begin{array}{c}\text { Mean } \\
\text { Difference }\end{array}$} & \multicolumn{2}{|c|}{$\begin{array}{l}95 \% \text { Confidence } \\
\text { Interval of the } \\
\text { Difference }\end{array}$} \\
\hline & & & & & & & Lower & Upper \\
\hline$<10$ & 22 & 30.50 & 8.06 & 27 & 0.065 & 3.50 & -0.07 & 7.07 \\
\hline 11-20 & 52 & 30.25 & 8.01 & 27 & 0.005 & 3.25 & 1.01 & 5.48 \\
\hline 21-30 & 31 & 31.93 & 8.58 & 27 & 0.003 & 4.93 & 1.78 & 8.08 \\
\hline$>\mathbf{3 0}$ & 15 & 34.86 & 8.99 & 27 & 0.004 & 7.86 & 2.88 & 12.84 \\
\hline
\end{tabular}

The first two workload interval groups including 105 teachers with less than 30 teaching hours are significantly faced with depersonalization while the groups with teaching hours of more than 30 are not as it is presented in table 6.

Table 6

Statistics and one-sample t-test for Depersonalization with reference to workload

\begin{tabular}{|c|c|c|c|c|c|c|c|c|}
\hline \multirow{3}{*}{$\begin{array}{c}\text { Workload } \\
\text { Hours/Week }\end{array}$} & \multicolumn{8}{|c|}{ Depersonalization } \\
\hline & \multirow[t]{2}{*}{$\mathbf{N}$} & \multirow[t]{2}{*}{ Mean } & \multirow[t]{2}{*}{ SD } & \multirow[t]{2}{*}{$\begin{array}{c}\text { Test } \\
\text { Value }\end{array}$} & \multirow[t]{2}{*}{$\begin{array}{l}\text { Sig. (2- } \\
\text { tailed) }\end{array}$} & \multirow[t]{2}{*}{$\begin{array}{c}\text { Mean } \\
\text { Difference }\end{array}$} & \multicolumn{2}{|c|}{$\begin{array}{l}95 \% \text { Confidence } \\
\text { Interval of the } \\
\text { Difference }\end{array}$} \\
\hline & & & & & & & Lower & Upper \\
\hline$<\mathbf{1 0}$ & 22 & 17.40 & 6.38 & 13 & 0.004 & 4.40 & 1.57 & 7.24 \\
\hline 11-20 & 52 & 17.63 & 6.41 & 13 & 0.001 & 4.63 & 2.84 & 6.42 \\
\hline 21-30 & 31 & 15.74 & 5.54 & 13 & 0.010 & 2.74 & 0.70 & 4.77 \\
\hline$>\mathbf{3 0}$ & 15 & 14.40 & 5.44 & 13 & 0.337 & 1.40 & -1.61 & 4.41 \\
\hline
\end{tabular}

Finally, the teachers with less than 20 teaching hours show significant reduced personal accomplishment whereas the ones having more than 21 hours in the same period of time as the others do not seem to have personal accomplishment problems. 
Table 7

Statistics and one-sample t-test for Reduced Personal Accomplishment with reference to workload

\begin{tabular}{|ccccccccc|}
\cline { 2 - 9 } & \multicolumn{8}{c|}{ Reduced Personal Accomplishment } \\
$\begin{array}{c}\text { Workload } \\
\text { Hours/Week }\end{array}$ & $\mathbf{N}$ & Mean & SD & $\begin{array}{c}\text { Test } \\
\text { Value }\end{array}$ & $\begin{array}{c}\text { Sig. (2- } \\
\text { tailed) }\end{array}$ & $\begin{array}{c}\text { Mean } \\
\text { Difference }\end{array}$ & $\begin{array}{c}\text { 95\% Confidence } \\
\text { Interval of the } \\
\text { Difference } \\
\text { Lower }\end{array}$ \\
\hline $\mathbf{1 1 0}$ & 22 & 23.00 & 7.86 & 31 & 0.001 & -8.00 & -11.48 & -4.51 \\
$\mathbf{1 1 - 2 0}$ & 52 & 25057 & 7089 & 31 & 0.001 & -5.4 & -7.62 & -3.22 \\
$\mathbf{2 1 - 3 0}$ & 31 & 27.00 & 9.33 & 31 & 0.024 & -4.00 & -7.42 & -0.57 \\
$>\mathbf{3 0}$ & 15 & 30.66 & 7.98 & 31 & 0.874 & -0.33 & -4.75 & 4.09 \\
\hline
\end{tabular}

\section{DISCUSSION}

On the basis of the statistical findings presented in the preceding section, a high level of burnout is evident among English teachers in the public schools. In other words, they are emotionally exhausted and demonstrated high levels of depersonalization and reduced personal accomplishment. The results are also in line with two elaborated demographic factors which are age and workload.

Out of four age groups, the first three younger groups proved to be emotionally exhausted; however, the participants above 45 have not encountered such a problem. The first age group (i.e. participants below 25) demonstrated not to be troubled by depersonalization while the older ones showed signs of this syndrome. Interestingly, the first and the last groups verified to have low level of personal accomplishment. The majority in between (i.e. 61 percent of participants between the ages of 25 and 45) did not experience reduced personal accomplishment.

The findings reveal that the population aged 26 to 45 is more susceptible to both emotional exhaustion and depersonalization while they are more resistant to reduced personal accomplishment. On the other hand, the youngest group (i.e. below 25) suffers from emotional exhaustion and reduced personal accomplishment but their depersonalization was not highly reduced. The oldest teachers (i.e. above 45) seem to be highly affected by depersonalization and reduced personal accomplishment, yet not by emotional exhaustion.

Previous research findings achieved by Anderson and Iwanicki (1984); Crane and Iwanicki, (1983); McIntyre, (1981); Schwab and lwanicki, (1982) show that the younger the teachers are, the more burned out they would be in facing troubles probably caused by lack of professional experience; however, the outcome of this study is not confined to the youth but all age groups are affected in specific subscales of this syndrome.

Teaching workload reported by the teachers was the amount of hours per week categorized in four groups of 10- hour intervals. Those with more than ten hours per week wear out emotionally though the ones with less than 30 hours face depersonalization and reduced personal accomplishment. This shows that emotional exhaustion is controlled by less workload while more than 30 hours per week help teachers overcome depersonalization and reduced efficacy.

Since burnout brings about negative effects in the instructional system leading to unsuccessful students learning, it can be recommended that school administrators grant more opportunities of extra curricular activities to overcome the syndrome. Referring to the findings of this study, vulnerable age groups of teachers with high pressure of teaching workload ought to be under more attention. It might also be helpful if teachers do not have to be overloaded by teaching hours inside or outside of the school context. This probably requires a plan that provides higher salary for limited teaching load with strict regulations preventing teachers from working further. 


\section{AUTHOR INFORMATION}

Dr. Jayakaran is now Associate Professor at the Faculty of Educational Studies where his main teaching and research areas are in Teaching of Writing ELT Materials and Professional Development in ELT. He is a Director of the Extensive Reading Foundation (ERF) and Visiting Fellow at Leeds Metropolitan University, UK. He founded MICELT (The Malaysia International Centre for English Language Teaching) and has organized international conferences for more than 10 years. He also manages web-sites for MICELT (www.micelt.com.my) and The Faculty Resource Centre which he heads (www.sumberfpp.com.my). He works on several social projects including a scholarship project for ELT.

Koroush Khandehroo has degreed in English Language Translation and mastered in English Language Teaching from Islamic Azad University, Iran. He has been lecturing in Islamic Azad University, Neyshaboor branch for 7 years in the English department instructing preparatory general English courses as well as TESL ones. His research interest areas are Professional Development, Form-Focused Instruction and Noticing, and Incidental Vocabulary Acquisition. He is now a PhD candidate in the field of TESL at Universiti Putra Malaysia (UPM). His major focus of research now is "English Language Teacher's Professional Development Needs".

\section{REFERENCES}

1. Anderson, M.B., and lwanicki, E.F., Teacher motivation and its relationship to burnout. Educational Administration Quarterly, Vol. 20. No.2, pp. 94-109, 1984.

2. Byrne, B. M., The homological network of teacher burnout: A literature review and empirically validated model. In R. Vandenberghe and A. M. Huberman (Eds.), Understanding and preventing teacher burnout (pp. 15-37). Oxford, England: Cambridge University Press, 1999.

3. Crane, S., and lwanicki, E.F., The effect of role conflict and role ambiguity on perceived levels of burnout among special education teachers. A paper presented at the American Educational Research Association. Montreal, Canada, 1983.

4. Freudenburger, H. J. and North G., Women's burnout: How to stop it, how to reserve it and how to prevent it. R. R. Donneley and Sons Company, Virginia, USA, 1985.

5. Gavrilovici, L. O., Romanian teachers' burnout and psychological and professional difficulties, The Internet: http://holon.ladipu.com/resources/15//Romanian\%20teachers'\%20burnout\%20and\%20.pdf, 2007.

6. Gold, Y., Roth, R. A., Wright, C. R., Michael, W. B., and Chen, C. Y., The factorial validity of a teacher burnout measure (educators' survey) administered to a sample of beginning teachers in elementary and secondary schools in California. Educational and Psychological Measurement, Inc., Vol. 53, pp. 761-768, 1992.

7. Lau, P. S. Y., Yuen, M. T., and Chan, R. M. C., Do demographic characteristics make a difference to burnout among Hong Kong secondary school teachers? Social Indicators Research, Vol. 71, pp. 491-516, 2005.

8. Maslach, C. and Pines, A., Experiencing social psychology: Readings and projects. Alfred A. KNOPF, Inc., 1984.

9. Maslach, C., and Jackson, S. E., The Maslach Burnout Inventory. Palo Alto, CA: Consulting Psychologists Press, 1981.

10. Maslach, C., and Jackson, S. E., Burnout in health professions: A social psychological analysis. In G. Sanders and J. Suls (Eds.), Social psychology of health and illness, 1982.

11. Maslach, C., and Jackson, S.E., MBI: Maslach Burnout Inventory; Manual Research Edition (2nd ed.). Palo Alto, CA: Consulting Psychological Press, 1986

12. McIntyre, T.F., An investigation of the relationships among burnout, locus of control, and selected personal/ professional factors in special education teachers. Dissertation Abstracts International, 42/09, 3949A. (Order No. DA 8205164), 1981.

13. Rosenberg, T. and Pace, M., Burnout among mental health professionals: Special considerations for the marriage and family therapist. Journal of Marital and Family Therapy Vol. 32, No. 1, pp. 87-99, 2006.

14. Schwab, R. L., and Iwanicki, E. F., Who are our burned out teachers? Educational Research Quarterly, Vol. 7, pp. 5-16, 1982.

15. Schwab, R. L., Schuler, R. S., and Jackson, S.E., Educator burnout: sources and consequences. Education Research Quarterly, Vol. 7, pp. 14-30, 1986. 